\title{
Diferenças (sutis) e desigualdades (insofismáveis): breve reflexão sobre etnicidade e homossexualidade a partir de um estudo de caso
}

\author{
Martinho Tota \\ Universidade Federal do Ceará
}

Resumo: $\mathrm{O}$ presente artigo tem por objetivo refletir teórica e etnograficamente sobre os possíveis cruzamentos entre etnicidade e homossexualidade, tomando como contexto empírico o município paraibano de Baía da Traição, no estado da Paraíba, onde está localizada uma das Terras Indígenas Potiguara. Tendo as interseccionalidades como mote inspirador, busco aqui problematizar também um outro tipo de cruzamento, desta vez envolvendo diferenças culturais e desigualdades sociais.

Palavras-chave: Etnicidade; Homossexualidade; Diferença; Desigualdade. 


\title{
(Subtle) Differences and (Unmistakable) Inequalities: Brief Reflection on Ethnicity and Homosexuality - a Case \\ Study
}

\begin{abstract}
This article aims to reflect theoretical and ethnographically about the possible intersections between ethnicity and homosexuality, taking as empirical context Baía da Traição, in Paraiba (Brazil), where is located one of the Indigenous Lands Potiguara. Having the intersectionalities as inspiring motto, I seek here also discuss another type of cross, this time involving cultural differences and social inequalities.
\end{abstract}

Keywords: Ethnicity; Homosexuality; Difference; Inequality.

\section{Diferencias (sutiles) y desigualdades (innegables): breve reflexión sobre etnicidad y homosexualidad a partir de un estudio de caso}

Resumen: Este artículo tiene como objetivo presentar una reflexión teórica y etnográfica sobre los posibles cruzamientos entre la etnicidad y la homosexualidad, tomando como contexto empírico el municipio de Baía da Traição en el estado de Paraíba, Brasil, donde se encuentra una de las tierras indígenas Potiguara. Teniendo las interseccionalidades como lema inspirador, busco aquí también hablar sobre otro tipo de cruce, esta vez con las diferencias culturales y las desigualdades sociales.

Palabras clave: Etnicidad; Homosexualidad; Diferencia; Desigualdad. 


\section{Introdução}

O presente artigo é fruto de pesquisa realizada entre 2009 e 2010 no município de Baía da Traição, situado no Litoral Norte da Paraíba, onde encontramos uma das três Terras Indígenas Potiguara, constituída por 14 aldeias1. A referida pesquisa, que resultou em minha tese de doutoramento em antropologia social, teve como escopo e fio condutor compreender as possíveis articulações envolvendo gênero, geração, sexualidades e etnicidade em um contexto interétnico/intersocietário. Um dos principais eixos abordados ao longo da investigação etnográfica (porém não o único) consistiu na problematização das vivências de homens (índios e não-índios) autodenominados homossexuais ou gays em sua conexão com o fator étnico. A priorização deste eixo justificava-se como exercício compreensivo/interpretativo consubstanciado nas teorias relativas às interseccionalidades como campo epistêmico (cf. BRAH, 2002; BRAH e PHOENIX, 2004; MCCLINTOCK, 2010), sendo este, portanto, aquele que inspira a discussão aqui proposta.

Interessa lembrar que, em termos metodológicos, a pesquisa empreendida foi orientada etnograficamente, segundo o que se tornou um axioma fundamental da disciplina antropológica. É importante registrar isso, uma vez que nesta investigação procurei apreender o "outro", a alteridade, a diferença. Entretanto, ainda que eu tenha logrado êxito nessa busca pela alteridade, a diferença, a grande "Diferença" - que muitas vezes se confunde com o exótico consagrado na história da disciplina - não foi encontrada. Por outro lado, se tal diferença apareceu nuançada, sutil, as desigualdades sociais emergiram de maneira bastante enfática. E é justamente isto que gostaria de explorar aqui: a equação formada pelos "tropos" diferença, desigualdade, etnicidade e homossexualidade. Para tanto, penso ser necessário revisitar alguns textos dedicados ao fenômeno étnico e, num segundo momento, refletir a respeito do que está em jogo quando meus interlocutores acionam e operam com a categoria "homossexualidade". Creio que, após revolver os terrenos desses dois campos temáticos, estaremos em condições de enxergar se e como estes marcadores identitários (o étnico e o sociossexual) se cruzam.

\section{Etnicidade}

O fenômeno étnico é um produto histórico, teórico, sociocultural e político. Não cabendo no espaço deste artigo tentar uma genealogia dessa problemática, pretendo neste tópico apenas revisar ligeiramente trabalhos de alguns poucos autores que, cada um à sua maneira, contribuindo para a reflexão deste tema, apresentaram distintas perspectivas por meio das quais podemos visualizar um "mesmo" assunto.

1 Não havendo espaço aqui para detalhar informações históricas e de morfologia social da coletividade Potiguara, restame indicar os trabalhos de Amorim (1970), Azevedo (1986), Moonen e Maia, (1992), Palitot (2005), Vieira (2001) e o meu (TOTA, 2012). 
O termo "étnico" em si mesmo, já conhecido dos antigos gregos (como ethnos), servia para designar os estrangeiros e seus costumes "bárbaros". Na Europa medieval, os pagãos eram tidos como integrantes de um grupo ethnicus (cf. POUTIGNAT \& STREIFF-FENART, 1998: 23). No âmbito das ciências sociais, Max Weber (1991), ainda que não tenha sido o primeiro a formular uma definição acerca dos grupos étnicos, consta como uma referência ubíqua nos trabalhos dedicados ao tema. As características apontadas por este autor, definidoras desses grupos, continuam a ser evocadas - mesmo que apresentando ênfases variadas - na literatura sobre tal fenômeno. Dentre estas características encontram-se as fronteiras instauradas entre coletivos étnicos a ponto de muitos destes "isolarem-se monopolisticamente". Os processos de fronteirização, responsáveis por tal isolamento, encontrariam sua fonte no sentimento coletiva e subjetivamente compartilhado pelos indivíduos de que estes teriam em comum uma origem, hábitos, costumes, honra e dignidade capazes de uni-los e, concomitantemente, diferenciá-los de outros coletivos. De acordo com Weber (1991), no entanto, mais que uma "comunidade", um grupo étnico propiciaria a instauração de relações comunitárias, sobretudo de natureza política, pois seria dentro deste campo de ação (instituído por meio de um conjunto de práticas racionais) onde se engendraria a crença numa possível comunhão étnica e, por conseguinte, uma “comunidade de intercâmbio social”.

Apesar da contribuição dada por Weber (1991), suas ideias não se difundiram muito nos anos que se seguiram ao seu Economia e Sociedade, publicado originalmente em 1922. De acordo com Poutignat \& Streiff-Fenart (1998: 17 e 24), isso só viria ocorrer na década de 1940, quando a etnicidade, instrumentalizada em referência a grupos não anglo-americanos, passou a ser vista como princípio de divisão da vida social (cf. STOLCKE, 1993: 23-25, 2930). A partir dos anos 1970, o centro das atenções dos antropólogos interessados na temática étnica passou a ser a questão das fronteiras, a qual adquiriu um outro patamar heurístico com os trabalhos de Barth $(1998,2000)$, o qual desloca a ênfase até então conferida aos "conteúdos" étnicos rumo aos espaços e contextos intersticiais envolvendo grupos ou sociedades etnicamente diferenciados. Para o autor, tal procedimento analítico se justificaria pelo fato de que as "fronteiras persistem apesar do fluxo de pessoas que as atravessam" (BARTH, 1998: 188, 194). Em meio a esse processo dinâmico, as distinções de categorias étnicas se inscrevem num quadro de mobilidade, contato e informação e, a despeito de sua fluidez e dinamicidade, as diferenças intergrupais, longe de serem apagadas, são criativa e politicamente construídas e performadas no vestuário, na língua, na moradia, nos padrões de moralidade pelos quais as ações são julgadas. Nesse sentido,

\footnotetext{
as categorias étnicas fornecem um cadinho organizacional dentro do qual podem ser colocados conteúdos de formas e dimensões várias em diferentes sistemas socioculturais. Tais categorias podem ter grande importância para o comportamento e permear toda a vida social dos sujeitos, mas também podem ser relevantes apenas para setores limitados de atividade (BARTH, 2000: 32-33).
}

Para Barth, portanto, uma identidade étnica não coincide necessariamente com um modo de vida específico nem com um grupo real de pessoas, mas tem a ver com a "natureza circunstancial da escolha de uma identidade étnica em meio a outras escolhas de identificação possíveis" (POUTIGNAT \& STREIFFFENART, 1998: 63-64).

Um dos méritos da proposta barthiana foi enxergar no fenômeno étnico seu aspecto eminentemente situacional e dinâmico, o que foi seguido por um 
contingente cada vez mais numeroso de pesquisadores (cf. NAGATA, 1974; OKAMURA, 1981; ERIKSEN, 1991 e muitos outros). No Brasil, intelectuais do porte de Cardoso de Oliveira (1976) - um dos primeiros a difundir a perspectiva analítica de Barth no país - saudaram o autor entusiasticamente e, desde então, seus postulados vêm inspirando gerações de estudiosos (cf. BARRETO FILHO, 1993; GRÜNEWALD, 1993; PACHECO DE OLIVEIRA, 1988, 2004, entre outros). Todavia, a teoria barthiana, a despeito de seu prestígio, jamais se constituiu em unanimidade.

Charles Keyes (1976), por exemplo, discorda das definições "culturalistas" e situacionais da etnicidade. Às vezes tachado de "primordialista", o fato é que este autor traz à baila uma questão pertinente, qual seja: a ideia de que a descendência comum funciona como fator "primordial" para a definição do étnico. Numa crítica dirigida a Barth, Keyes (1976: 203) afirma que, ao priorizar o caráter situacional da etnicidade, o fator étnico acaba sendo uma questão inteiramente arbitrária e sem valor analítico. Tendo isso em mente, Keyes (1976: 204-210) enfatiza os "fatos do nascimento" - sexo, características biológicas, data e local de nascimento e, sobretudo, linha de descendência como o fundamento da etnicidade, uma vez que é a partir destes "fatos" que os indivíduos e grupos criam diferenciações e constroem um "um senso identitário".

Igualmente inquietado com a proposta barthiana, Dan Aronson (1976) se pergunta: “o que é ‘étnico' em relação aos grupos étnicos?”. Para ele, se não há nada que divida substancialmente a "classe" étnica da não-étnica, deveríamos abandonar o uso do termo. Na verdade, Aronson (1976), como Barth (1998), sustenta que as identidades étnicas são construídas interativamente; que estas, longe de essenciais, são situacionais. Entretanto, o que move os sujeitos numa arena conflitiva interétnica são os "interesses políticos". Enfatizando o uso "político das 'diferenças", Aronson (1976) propõe que a etnicidade seja vista como "um tipo particular de ideologia", uma ideologia "do e para o dissenso, para a autonomização de valores em uma arena sociopolítica inclusiva”. Ao contrário das ideologias de classe (que assumem ou buscam por valores consensuais)

\footnotetext{
uma ideologia étnica diz que não concordamos com os valores últimos do sistema. Do ponto de vista dos indivíduos, precisamos analisar como diferentes ideologias relativas às suas 'identidades básicas, mais gerais', algumas étnicas e outras não, se articulam umas com as outras em situações iguais ou diferentes, de forma que possamos julgar os efeitos de fidelidades conflitantes, clivagens cumulativas e assim por diante (ARONSON, 1976: 14).
}

Os autores acima mencionados e outros tantos colocam a existência dos grupos étnicos como problemática e, a despeito das divergências entre eles, as correntes teóricas que representam "apontam para dimensões constitutivas, sem as quais a etnicidade não poderia ser pensada" (PACHECO DE OLIVEIRA, 2004: 32-33). Quanto aos "índios do Nordeste" brasileiro, o que esta literatura tem a nos dizer? Para Martins (2004: 227-228), tudo, uma vez que "a questão indígena [nessa região do país] está fundamentalmente vinculada a um contexto político contemporâneo, ligado a situações de territorialidade e de identificação étnica". De acordo com a autora, a "indianidade tem se dado através da utilização de um etnônimo específico, estabelecendo fronteiras étnicas através de sinais diacríticos". Quanto à territorialidade, esta "vem sendo realizada através de conquistas de parcelas de terras". Martins não desconsidera fatores outros, como as relações e/ou os discursos invocando relações de parentesco 
(reais ou não, como diria Keyes [1976]) e a religiosidade, ambos muitas vezes associados ao elemento político.

Quanto aos índios Potiguara, as análises não fogem desse contexto teórico. Para Azevedo (1986) e Palitot (2008), a díade Estado/luta pela terra

\begin{abstract}
formou a base para o advento de uma 'identidade étnica' do grupo. Isso porque, na luta para conferir legitimidade à posse do território pelos índios, estes tiveram de acionar discursos demarcando sua diferença em relação aos demais atores com os quais tinham de conviver na região onde viviam e atualizar o passado de dominação e resistência por eles experienciado (AZEVEDO, 1986: 41-42).
\end{abstract}

Segundo Palitot (2008: 4-9), antes da mobilização para terem garantido o acesso irrestrito ao território por eles ocupado, muitos potiguaras "escamoteavam" sua identidade étnica. De acordo com ele, foi a luta pela terra que ensejou uma "emergência étnica, articulando novos sentidos e práticas a velhas memórias silenciadas durante séculos de repressão". Por essa razão, a configuração deste coletivo étnico traduzir-se-ia a partir de elementos de natureza econômica, política, cultural e moral bem como nas relações deste com o Estado brasileiro (PALITOT, 2005).

Nos discursos emitidos por muitos de meus/minhas interlocutores/as, evocando termos como "cultura", "comunidade", "povo" e "sangue"; na importância conferida por muitos ao local de moradia e nascimento; no fato de terem ambos os genitores indígenas ou "ancestrais" ilustres, que "lutaram" em defesa de seu "território"; na ênfase posta por alguns à "espiritualidade"; na reivindicação por "direitos", como acesso à saúde, educação, conhecimento, informação, emprego e fontes de renda; na noção de "respeito" à sua diferença perante os não-índios; na própria organização política do grupo, com seus caciques e as inúmeras associações (de artesãos, professores, mulheres, jovens, entre outras); na participação de muitos no movimento indígena nacional, nas assembleias e manifestações públicas em diversas partes do Brasil, sobretudo em Brasília; na prática ritual do Toré; na história de heroísmo e perseguição, desde o período da Colonização, estava a etnicidade Potiguara.

\title{
Homossexualidade
}

Antes de dar início à pesquisa, uma questão me intrigava: em que medida a categoria "homossexual" caberia no contexto habitado por índios e não-índios na região onde está inserido o município de Baía da Traição? Haveria uma correlação direta entre desejos e práticas eróticas e a constituição de identidades sexuais ou de gênero? Tal categoria seria capaz de lançar algum rasgo de luz, ou, parafraseando Geertz (1978), estava eu simplesmente buscando pessoas sutis imbuído de meros pressupostos obtusos? Fato é que, para todos os meus interlocutores (índios e não-índios), a noção de homossexualidade não apenas era de seu conhecimento, sendo também acionada na constituição de um universo de significados referentes aos comportamentos e identidades sexuais. Por meio de "mexericos, calúnias, maledicências, insultos, elogios, acusações, críticas, polêmicas, louvações” (BOURDIEU, 1996: 81), a homossexualidade era por eles elaborada. Não obstante as variações semânticas e biográficas, em linhas gerais, para eles, esta palavra dizia algo de suas identidades, as quais começaram a ser construídas a partir mesmo do "nascimento": "A gente nasce homossexual", conforme muitas das pessoas ouvidas. Tal percepção ganhava vida nas reminiscências, quando os sujeitos retornavam a uma infância povoada 
por brincadeiras, por sensações ainda sem nome e pela convivência (nem sempre harmoniosa) com os pais.

O sentimento de "diferença", portanto, nascia aí, não muito tempo depois dos sujeitos. Simões (2004: 432-433) observa que muitos homossexuais constroem uma "trama que estrutura os acontecimentos numa narrativa mais ou menos coerente, capaz de oferecer um senso de continuidade de si e do lugar social". Interpretada como um aspecto intrínseco ao "eu", a homossexualidade, contudo, não deixava de ser criativamente elaborada pelos sujeitos diante de um corpus de sensibilidades - a dor, o sofrimento, desejos incompreendidos, sensações corpóreas, prazeres -, mas também no âmbito da relacionalidade. Nesta segunda instância, era na tensão com os pais, nos comentários e nas reações de outros familiares, de colegas da escola, de pessoas conhecidas na aldeia ou na cidade; na convivência com um grupo de pares e nas relações eróticas e/ou afetivas com pessoas do mesmo sexo - as quais poderiam ser um primo, um tio, um vizinho, geralmente mais velho - que se dava a percepção de uma sexualidade à margem da heteronormatividade. $O$ insulto aqui cumpria um papel central. A partir dele se veiculava a mensagem de que estes indivíduos possuíam uma "dada qualidade", de que estes deveriam comportar-se "em conformidade com a essência social que lhe[s] é assim atribuída" (BOURDIEU, 1996: 82).

Mas em que consistia tal "qualidade"? Ora, a "qualidade" era traduzida nos atos, nas "brincadeiras de menina", no "jeitinho", ou seja, nas performances de gênero: uma "abominação" de caráter individual visível nos corpos (GOFFMAN, 1988: 14), cobrando dos sujeitos um "cuidado de si" (cf. FOUCAULT, 1985: 50) constante. E porque tal escrutínio advinha das reações dos outros importantes, o peso das práticas sexuais per se era relativo. Afinal, embora a gramática da "passividade"/"atividade" estivesse presente nos discursos da grande maioria dos atores ouvidos, não era a prática sexual que demarcava a fronteira entre um "homem pela metade" e um "homem mesmo". As falas de meus interlocutores levavam-me ao encontro das considerações de Leal (2005: 73), para quem "[a] classificação das práticas [sexuais] demonstra que as restrições devem ser contextualizadas, pois são relativas a um determinado momento ou ao modo como um parceiro está sendo posicionado ou pensado naquela relação". As informações etnográficas, portanto, me faziam crer que o engessamento das práticas sexuais em dicotomias estanques ("passivos" $\mathrm{x}$ "ativos"; "femininos" $\mathrm{x}$ "masculinos"; "dominados" x "dominadores") era insuficiente para distinguir as identidades sociossexuais dos sujeitos. Para além delas estavam as performances de gênero, a "escolha do objeto sexual", as emoções atreladas a tal "objeto" e, acima de tudo, a maneira como cada um interpretava estas questões.

Importante registrar, contudo, que, levando em conta os vocabulários ou práticas linguísticas, que "criam ou reproduzem subjetividades diversas" (COSTA, 1992: 14-15), observamos no contexto em foco um universo simbólico construído polissemicamente. Prova disso foram as diversas outras categorias acionadas pelos atores e que eram mais ou menos aproximadas à noção de homossexualidade, tais como "bicha", "fresco", "frango", "viado", "gay", "entendido", "biba". Os campos semânticos destas palavras se sobrepunham, de modo que as mesmas apareciam sinonimicamente. Todavia, em que circunstâncias eram utilizadas e por quem? Vejamos a tabela abaixo: 


\begin{tabular}{|c|c|c|}
\hline $\begin{array}{c}\text { Terminologia } \\
\text { (auto)classificatória }\end{array}$ & Quem usa & Contexto \\
\hline "Homossexual" & $\begin{array}{c}\text { Homossexuais e não- } \\
\text { Homossexuais }\end{array}$ & $\begin{array}{l}\text { Formal, polido. Palavra tida } \\
\text { como "politicamente correta". } \\
\text { Acionada durante entrevistas } \\
\text { formais, tal categoria emergia } \\
\text { como definidora de uma } \\
\text { identidade sociossexual, } \\
\text { apresentando um teor positivado } \\
\text { quanto à mesma. }\end{array}$ \\
\hline "Gay", "entendido" & Homossexuais & $\begin{array}{l}\text { Informal, espontâneo. Usadas } \\
\text { por sujeitos mais jovens, isto é, } \\
\text { com menos de } 30 \text { anos. }\end{array}$ \\
\hline $\begin{array}{c}\text { "Bicha", "viado", } \\
\text { "fresco", "frango", } \\
\text { "biba" }\end{array}$ & $\begin{array}{l}\text { Homossexuais e não- } \\
\text { Homossexuais }\end{array}$ & $\begin{array}{l}\text { Termos empregados em } \\
\text { situações informais, cotidianas. } \\
\text { Quando usadas por sujeitos não- } \\
\text { homossexuais, tais expressões } \\
\text { eram emitidas com tons } \\
\text { claramente depreciativos ou } \\
\text { jocosos. Entre homossexuais, } \\
\text { acionadas nas interações } \\
\text { amistosas envolvendo amigos ou } \\
\text { com sentido pejorativo em } \\
\text { relação a desafetos também } \\
\text { homossexuais. }\end{array}$ \\
\hline
\end{tabular}

Nesse sistema classificatório, elaborado contrastivamente pelos atores que colaboraram com a pesquisa, também havia os "homens", "homens de verdade", "homens mesmo", "bofes", "boys", "boyzinhos", "machos", designativos dos indivíduos com quem interagiam ou poderiam interagir sexualmente, os quais se contrapunham aos "homossexuais", "gays", "entendidos", "bichas", "viados", "frescos", "frangos", "bibas". Até mesmo quando referidas à anatomia dos corpos e às práticas sexuais, as palavras criavam e traduziam relações, aludindo a um corpus de ações e contra-ações prazerosamente engendradas num universo sensível construído pelos sujeitos.

A depender dos contextos interativos (formais ou informais), dos atores envolvidos (homossexuais e/ou não-homossexuais), de seus status sociais, de suas idades e níveis de escolaridade, de acordo com a natureza dos vínculos relacionais (eróticos/afetivos, de amizade ou inimizade) criados por e entre eles, os sentidos destas palavras variavam. Respeito/desrespeito, afirmação/negação, jocosidade/discriminação eram alguns dos elementos que entravam em jogo, situacionalmente, quando o assunto em questão eram as sexualidades, masculinidades e feminilidades. Atentar para esta diferença, ainda que sutil, permitia observar a ocorrência de estratificações e hierarquizações de ordem sexual e social, hierarquias estas operadas não apenas em termos duais ("homens pela metade" x "homens mesmo"), mas entre "homens" e "homens", "homossexuais" e "homossexuais". As assimetrias aqui não negavam 
reciprocidade; afinidades não solapavam diferenças; o desejo não subjugava a cruel injúria e a amizade não apagava conflitos.

\section{(Onde) etnicidade e sexualidade se cruzam?}

Qual a relação entre sexualidade, gênero, etnicidade, raça e nacionalismo, se pergunta Nagel (2003) na introdução de seu livro? Se fizermos uma digressão histórica, percebemos que, desde o início do processo colonizador nas Américas, questões étnico-raciais foram vistas também sob uma ótica onde estava em jogo o que hoje conhecemos por relações de gênero e sexo. A suposta licenciosidade dos silvícolas brasileiros constituiu apenas um dos atributos por meio dos quais estes foram exotizados, vistos como não humanos; ou, por outro lado, permitiu a construção das imagens do "bom selvagem, sem pecado e sem juízo". As políticas indigenistas empreendidas primeiramente pela Coroa Portuguesa e, depois, pelo Império Brasileiro - objetivando a extinção dessas populações ou sua "assimilação" por meio do sistema de aldeamentos e da imposição dos casamentos interétnicos - ilustram o quanto noções de raça estiveram desde sempre imiscuídas em preceitos religiosos, nos ideais de soberania e civilização, nas imagens estereotipadas das sexualidades dos povos autóctones e o quanto a regulação e o disciplinamento dessas sexualidades eram importantes para os projetos de conquista e, posteriormente, para a formação de um Estado-Nação (cf. KODAMA, 2005). Nesse contexto, também a "sodomia" foi acionada pelos conquistadores ibéricos como justificativa para subjugar as populações ameríndias (cf. TREXLER, 1995).

No Brasil, ao longo dos séculos XIX e XX, os anseios de construção de uma "Identidade Nacional" levou intelectuais, políticos e literatos a buscarem na raça, na cor, no temperamento (cordial?), no "jeitinho", nos costumes, algo capaz de representar uma "brasilidade genuína". Nessa "feijoada", o comportamento sexual, diretamente atrelado a estereótipos raciais e nacionais, esteve igualmente presente. Vejamos, por exemplo, a obra de Gilberto Freyre e sua leitura do "luso-tropicalismo", fruto da conjugação "perfeitamente equilibrada" entre "indivíduos de cultura européia, africana e ameríndia", que enriqueceram a "cultura" brasileira com "espontaneidade", "frescor de imaginação", "emoção", "liberalidade", "intercomunicação e até a fusão harmoniosa de tradições diversas", fazendo do "regime brasileiro um dos mais democráticos, flexíveis e plásticos" do mundo (FREYRE, 1994: 52).

A observação de Harding (apud STOLCKE, 1993: 23) - qual seja: a de que em sociedades altamente estratificadas social e racialmente, sobretudo aquelas com um passado colonial e escravista - como a brasileira -, "gênero é também uma categoria racial e raça uma categoria de gênero" - aplica-se perfeitamente ao quadro histórico a que me refiro. Desigualdades sociais, de gênero e sexo foram construídas e naturalizadas historicamente para perpetuar desigualdades (STOLCKE, 1993: 30). Segundo Moore (2000: 34-35), as estruturas de poder se fundam em distinções raciais que são muitas vezes utilizadas para sobredeterminar e substituir outras formas de diferença. Assim, os idiomas de gênero e raça são usados para ordenar diferenças de poder e/ou prestígio, em 
que o próprio poder é representado em muitos contextos como sexualizado e racializado, engendrando uma masculinidade e um racismo hegemônicos, ligados à ascensão do poder econômico e político, sendo parte de um discurso ocidental sobre o "outro" (cf. NAGEL, 2003; YOUNG, 2005).

Ironicamente, na contemporaneidade, ao menos no caso dos índios vivendo no Nordeste brasileiro, o que se deu foi uma completa disjunção entre o discurso étnico e questões referentes a gênero e, principalmente, sexualidade. Houve - o que não deixa de ser compreensível em termos políticos - uma produção abundante enfocando o primeiro termo desta equação e um total apagamento de outras instâncias da vida social desses coletivos. Com isso, vemos em diversas monografias o que Alcida Ramos (1991) chamou de "índio hiper-real", inserido em uma conjuntura ideológica na qual "se ignora a alteridade das pessoas que existem em carne e osso" (RAMOS, apud FONSECA, 2000: 225).

Supostamente "imparciais" e "objetivas", as disciplinas acadêmicas, contudo, contribuíram para a instauração e continuidade deste quadro (cf. SAID, 1978). Em sua leitura de Bourdieu (1984), Canclini (2007: 138-139) chama atenção para o fato de que os "temas da moda estabelecem-se, em parte, por exigências provenientes da dinâmica própria do conhecimento, mas também por relações de solidariedade e cumplicidade entre os membros de cada instituição". Desse modo, a "autoridade epistemológica" muitas vezes se constitui

pela maneira como a organização do campo antropológico estabelece o que deve ser estudado e o que ficará excluído. Assim se configura em cada época o que seria próprio da antropologia e se expulsam partes da problemática social para o terreno da história, da sociologia e do que simplesmente não vale a pena pensar (CANCLINI, 2007: 138-139).

Por conseguinte, no esforço de retratar "índios hiper-reais", homens e mulheres apenas como "sujeitos étnicos" - oscilando entre a docilidade e a bravura -, muitas etnografias tendem a retratar estes atores como se destituídos de sexualidade e de tudo o que esta palavra envolve.

Não se trata, contudo, de um processo unilateral. Certamente muitas lideranças de coletividades indígenas não veem nenhuma vantagem em ter os etnônimos que representam associados a indivíduos cujos comportamentos escapam à heteronormatividade. Quando Pablo, um de meus interlocutores, me confidenciou o diálogo por ele ouvido entre duas lideranças indígenas, as quais afirmavam categoricamente não haver "potiguara fresco", a leitura que fiz levava-me justamente à tensão histórica e contemporânea relacionada à intersecção entre etnicidade/indianidade e sexualidade. Assim, poderíamos interpretar como "natural" o discurso emitido por estas duas lideranças; afinal de contas, nada mais prejudicial a um coletivo indígena, historicamente subjugado política e socialmente, do que ter sua imagem "manchada" pelas condutas sexuais "inadequadas" de alguns sujeitos. Sim, era "natural" que Pablo, assim como André (outro de meus interlocutores), não conseguisse emprego como professor por não gozar de uma boa "reputação". Ora, que importavam estas pessoas e seus discursos contra a "homofobia" e o "machismo", o "preconceito" e a "discriminação"? Não, certamente meus interlocutores não achavam isso "natural"; eles não queriam ser silenciados, apagados como se inexistissem. Prova disso eram os "ensaios" de ativismo empreendidos por Pablo, André e outros, cada qual à sua maneira, que buscavam denunciar os processos de exclusão pelos quais se sentiam afetados. 
Ora, seria mera coincidência o fato de estes sujeitos investirem tanto no discurso étnico e atuarem na esfera do movimento indígena, ao mesmo tempo em que expunham uma preocupação quanto à discriminação contra as homossexualidades? Talvez não. Se pensarmos como Lemert (2000), quando este afirma que "a identidade social envolve uma reivindicação de direitos num espaço social”, a postura destes atores não era nada ocasional. "Quem somos ou escolhemos ser", escreve Lemert (2000: 152),

é sempre uma determinação feita para nos localizar no espaço social ou, no caso daqueles a quem se atribuíra as localizações sociais inferiores, é, em certas condições de liberdade, a luta por definir uma localização onde antes não havia uma.

Assim, temos aqui um ponto de contato, onde etnicidade e homossexualidade se cruzavam no contexto etnográfico em foco. Tal cruzamento, como podemos observar, se dava numa tensão potencialmente disjuntiva. Ou seja, segundo uma visão etnicista heteronormativa, para alguns era necessário separar as duas coisas. Todavia, esta era apenas uma dentre as várias modalidades discursivas em que os dois marcadores identitários se cruzavam. Observando outras performances verbais, menos "politizadas", tínhamos uma "pan-homossexualização/homoerotização" envolvendo sujeitos homens na região da Baía da Traição; processo este que ora demarcava fronteiras étnicas, ora não. Essa dimensão apareceu nas falas de várias pessoas com quem tive contato, que afirmaram coisas do tipo: "Os Potiguara são gays"; "Aqui todos fazem"; "Não existem heterossexuais na Baía da Traição", e muitas outras. Um de meus interlocutores dizia acreditar que os índios eram mais "fogosos", enquanto outros informavam que alguns índios homossexuais eram mais "femininados" que os não-índios, se "emperiquitavam" e "rebolavam" mais, vestiam roupas de mulher e gostavam de "se divertir". Vemos então, nesses recortes discursivos, um processo de sexualização e generização étnico, ao menos referente aos homossexuais indígenas.

Ainda no âmbito comparativo, a conjugação entre etnicidade e homossexualidade tangenciava aspectos atinentes à "classe", "espaço" e "estilo de vida”. Refiro-me à classe aqui no sentido bourdiano do termo, isto é, algo que transcende o puramente econômico, abarcando, acima de tudo, o simbólico (BOURDIEU, 2007). Nesse sentido, as noções de classe e estilo de vida apareceram amalgamadas. Não deixa de ser curioso o fato de que, ao serem indagados a respeito de uma possível distinção categórica entre homossexuais indígenas e não indígenas, os sujeitos tenham acionado elementos insinuando a interrelação envolvendo questões direcionadas a estes termos. De modo geral, reunindo as falas de alguns entrevistados, os homossexuais não-índios viviam nas cidades grandes, tinham dinheiro e liberdade, viajavam, conheciam muitas pessoas e lugares. Quanto aos índios, estes eram pobres, viviam isolados nas aldeias; não tinham acesso à informação; desconheciam seus "direitos" e o que era experienciar um relacionamento amoroso "de verdade". Assim, tínhamos dicotomias multissituadas, porém atravessadas, do tipo: urbano/rural, rico/pobre, informados/desinformados; entre os que tinham mobilidade e aqueles (que se sentiam de certo modo) fadados ao imobilismo; entre os que gozavam de liberdade (inclusive para amar o mesmo sexo) e aqueles desprovidos de tal "direito".

Canclini (2007) me ajudou a empreender uma leitura mais detida acerca dessas questões. Tratando dos "recursos simbólicos e seus diversos modos de organização", o autor observa que estes "têm a ver com os modos de autorepresentar-se e de representar os outros nas relações de diferença e 
desigualdade, ou seja, nomeando ou desconhecendo, valorizando ou desqualificando". Para este autor, "[e]xiste uma problemática da desigualdade que se manifesta, sobretudo, como desigualdade socioeconômica”, mas também nas "condições desiguais de fixidez e mobilidade". Citando Boltanski \& Chiapello (2009), Canclini observa, no contexto de um mundo globalizado, que os “'grandes' [são] aqueles que dispõem de maior capacidade de se deslocarem nos espaços geográficos e interculturais, enquanto os 'pequenos' estão destinados à imobilidade", engendrando um novo processo distintivo e de exclusão, através do qual são estabelecidas divisões "entre os que se movem e os que ficam às inclinações caseiras, aos costumes ou às ideias fixas dos sedentários" (CANCLINI, 2007: 46, 57, 94). Para ele, diferenças, desigualdades e desconexão se complementam, e a privação de bens simbólicos, materiais e informacionais interfere diretamente nas "formas de pertencimento, posse ou participação". Aqui, até mesmo a dimensão afetiva deve ser considerada, uma vez que, por meio dela, "torna-se visível o peculiar sentido político de ações que não buscam a satisfação literal de demandas nem ganhos mercantis, mas reivindicam o sentido de certos modos de vida” (CANCLINI, 2007: 99-103, 224). Nas falas de alguns de meus interlocutores, ao representarem a diferença, havia um quê de denúncia das desigualdades e uma demanda por equidade.

\section{Entre diferenças e desigualdades}

O exposto no tópico anterior também ilustra a "veracidade" de um lado cruel presente nas vidas de muitos homossexuais - "nativos" ou não -, traduzido pelas mais diversas manifestações de "homofobia" e nas mais variadas formas de desigualdade, explicitadas ainda pelas noções contrapostas de "tolerância" e "respeito" evocadas por outros personagens ouvidos. Além disso, a co-existência de representações contrastantes que atravessavam o terreno ocupado pela questão homossexual revelava o quão variável poderia ser a vivência sexual e o modo como esta era percebida segundo cada ator. As noções de "respeito" e "discriminação", portanto, concerniam a fatores moleculares, isto é, embora sociais, eram diferencialmente elaborados pelos indivíduos.

Desviando o foco analítico, deparávamo-nos com outra esfera representacional, desta vez na comparação entre índios e não-índios. Frases do tipo: "Homossexual é homossexual; independente de raça, povo, etnia, crença, cultura", sintetizavam a maneira pela qual muitos interpretavam tal contraponto. $\mathrm{O}$ que estava embutido em afirmações como esta: um manifesto desconstrutivista tendo como alvo a alteridade ou o exercício criativo no sentido de engendrar novas formas de alteridade; uma estratégia política para não reproduzir estereótipos e gerar, consequentemente, a sobreposição de estigmas ou a visão daqueles que desfrutavam de uma vida menos atribulada do que aqueles que não tinham emprego, instrução, melhores condições de existência? Embora válidas, a maioria dessas respostas guarda em si um teor um tanto quanto maniqueísta. O fato é que, na prática - isto é, no contexto das interações entre meus interlocutores - e nas palavras, havia um conteúdo não diferencialista, pelo menos não em termos dicotômicos envolvendo sujeitos etnicamente diferenciados. Ou seja, nos comportamentos e atitudes cotidianas, nas relações entre amigos, colegas, namorados ou parceiros sexuais, o fator étnico simplesmente não era realçado. Para mim, seria impossível interpretar este fenômeno univocamente. 
Nesse sentido, voltemos ao terreno étnico, atentando para aspectos pouco enfatizados pelos autores citados na primeira parte deste artigo. Cohen (1978), Okamura (1981) e Eriksen (1991), por exemplo, estão entre aqueles que, de certo modo, levaram às últimas consequências a dimensão situacional do fenômeno étnico por contemplarem, além dos aspectos estruturais e interacionais, o lado "cognitivo", "subjetivo" contido na etnicidade. Okamura (1981) pensa nos atores individuais e no modo como cada um organiza e atribui significado à sua identidade étnica de acordo com as relações sociais estabelecidas em situações específicas. Sendo assim, o autor destaca a "dimensão cognitiva da etnicidade", isto é, as "percepções e entendimentos do ator" quanto aos "símbolos e signos culturais". Seguindo esta perspectiva teórica, a relevância conferida pelo indivíduo à sua identidade étnica variaria de acordo com cada situação interativa (Okamura, 1981: 465). A partir de um nível "mais baixo" de escrutínio, vemos que o componente étnico - bem como quaisquer marcadores identitários - é fluido, apresentando significados e sendo definido a partir de critérios variados. Sem desconsiderar a importância dos "status relativos, políticos e sócio-econômicos dos grupos, a distribuição das ocupações, a educação, a renda e outros recursos materiais e sociais", em suma, a dimensão estrutural, Okamura (1981) observa contudo que nem sempre a etnicidade importa nas mais distintas situações sociais:

Pode ser que em algumas a etnicidade seja um fator relevante que influencia a interação das partes, enquanto em outras situações a relação prossiga de acordo com outros atributos tais como classe, religião, ocupação, sexo, personalidade, etc. (OKAMURA, 1981: 452-458).

Nesse contexto, ao invés de enfatizar sua identidade étnica, o ator pode simplesmente manipulá-la, obscurecê-la, renunciá-la, optando por enfatizar outros aspectos identitários.

Certamente a questão de realçar ou apagar a identidade étnica não depende apenas da escolha individual dos sujeitos, mas também de fatores objetivos, dos "contextos nos quais as interações se situam" (POUTIGNAT \& STREIFF-FENART, 1998: 166-168), da posição ocupada e do status de cada ator. Isso não implica, porém, negar o poder reflexivo, cognitivo e emocional dos sujeitos. É isto o que Cardoso de Oliveira (2006: 79 e n. 40) procura mostrar retomando o termo "identidade renunciada", cunhado por Erik Erikson (1972), isto é, "uma identidade latente que (...) a qualquer momento pode ser atualizada, invocada". "Invocar" ou "renunciar" a uma identidade tem a ver com "ações providas de razoável taxa de racionalidade", afirma Cardoso de Oliveira (2006: 80-81), mas também com a "liberdade do sujeito ético", diz o autor, desta vez inspirado em James Laidlaw (2002). Trata-se, portanto, da "liberdade de uma decisão refletida", da "possibilidade de escolha do tipo de self que [o indivíduo] deseja ser" (LAIDLAW apud CARDOSO DE OLIVEIRA, 2006: 8384).

Refletindo à luz desta perspectiva teórico-analítica, podemos entender o porquê de muitos dos atores ouvidos enfatizarem ou "renunciarem" a certos tipos de identificação étnica, de modo a promoverem, reflexivamente ou não, uma disjunção entre etnicidade e sexualidade. Por outro lado, uma questão se mantinha: onde estaria a "diferença" entre homossexuais indígenas e não indígenas? Meus interlocutores responderam: em lugar nenhum. "São todos iguais, não tem diferença nenhuma. Se comportam do mesmo jeito", disse Geraldinho, outro de meus interlocutores, reproduzindo as falas de um grande número de pessoas. Mas como poderia ser de outro modo, em se tratando de 
uma coletividade com "baixo grau de distintividade cultural" (PACHECO DE OLIVEIRA, 1999: 99)? O autor desta expressão não endossa as teorias aculturativas, apenas observa que as populações indígenas no Nordeste brasileiro, como quaisquer outras, não vivem isoladas, imunes ao contato com outros grupos sociais. Os Potiguara não eram uma exceção à regra. Na verdade, todos os meus interlocutores tinham algum grau de instrução; muitos deles com ensino médio completo e/ou frequentando o ensino superior. Praticamente todos eles tinham aparelhos de televisão em suas casas, outros tantos possuíam telefones celulares. Não eram poucos os que participavam de redes sociais e tinham endereços eletrônicos. Mesmo os que viviam em aldeias mais afastadas da cidade mantinham contato com pessoas de outras localidades da Paraíba e outros estados brasileiros.

O papel desempenhado pelos meios de comunicação e informação emergiu, no decorrer do trabalho de campo, como uma questão a ser melhor investigada. Há uma literatura instigante dedicada ao assunto, onde se destaca a importância que a mídia e o consumo de determinadas imagens têm para a constituição de identidades que extrapolam fronteiras geográficas e culturais. Canclini (1999: 172-173), por exemplo, observa que questões de identidade social e/ou pessoal muitas vezes são respondidas pelo consumo de bens e dos meios de comunicação de massa. A partir da disseminação de imagens através da mídia, assistimos e vivenciamos a emergência de comunidades transnacionais de consumidores. Não se trata de meras cópias ou de processos homogeneizantes, mas do fato de que narrativas e identidades são coproduzidas (cf. APPADURAI, 1994).

Todavia, uma questão se mantinha: onde estaria a "diferença"? O que havia de "específico" no contexto aqui contemplado? Qual o papel desempenhado pela etnicidade/indianidade na agência de modos de "ser homossexual" dos atores com quem convivi ao longo do meu percurso etnográfico? Estas não foram perguntas minhas apenas, mas de alguns colegas e professores. Sem desconsiderar a argúcia contida neste tipo de questionamento, creio haver, implicitamente, o pressuposto de que seria possível estabelecer uma fronteira mais ou menos nítida, claramente diferençável, entre "eles" e "nós", ou entre "eles" e "outros". De minha parte, também operei com o mesmo pressuposto, imbuído de pré-noções dualistas (índios versus "brancos”), simplificando, portanto, uma realidade muito mais complexa e fugidia. Diversos autores (como HANNERZ, 1997; GEERTZ, 2000; BHABHA, 2001; KUPER, 2002) têm contribuído imensamente para o enriquecimento dos debates sobre o que está em jogo quando operamos com as categorias "Cultura", "Identidade" e com a noção de "Diferença”. Gupta \& Ferguson (1992), por exemplo, questionaram o modo como a noção de cultura tem sido operacionalizada no âmbito antropológico, como se esta coincidisse com fronteiras nacionais. Para estes autores, no tempo presente "o espaço foi reterritorializado" graças à mobilidade das pessoas, à produção e distribuição da cultura de massa (filmes, televisão, jornais, música, internet), o que erodiu particularidades culturais relacionadas a um lugar, sem levar contudo à temida homogeneização cultural global. Gupta \& Ferguson (1992) acreditam que "povos" e "culturas" persistem, porém não restritos aos mapas geopolíticos ou etnográficos.

A reflexão de George Marcus (1991) quanto às identidades culturais inserese no mesmo rol de problematizações com o qual lidam os autores citados. Para Marcus (1991: 216-217), esse "fenômeno disseminador" - a identidade - "possui uma vida própria" que vai além do espaço e do tempo onde "agentes humanos 
específicos" estão localizados. De acordo com este autor, mesmo num contexto local é possível

\begin{abstract}
captar a formação das múltiplas identidades num momento específico da biografia de cada ator e da história de um grupo de pessoas através da configuração de locais e contextos muito diferentes, reconhecendo as consequentes dispersões do sujeito (pessoa ou grupo) nos fragmentos múltiplos e sobrepostos" deste "espírito sem lar" que é a identidade (MARCUS, 1991: 204-205).
\end{abstract}

Se culturas e identidades distintas não desapareceram, a diversidade também não morreu. Os "estranhos" continuam a proliferar-se, já dizia Geertz (2000), a despeito da "suavização do contraste cultural", de sua palidez e estreiteza. Num contexto de espaços flexíveis, onde o semelhante e o diferente não ocupam territórios exclusivos, é no fortalecimento da nossa capacidade de imaginação para apreender o que está diante de nós que residem os usos da diversidade e de seu estudo. Em suma, no cenário atual, o "Nós” e o "Eles” já não podem mais ser pensados como entes fechados e homogêneos (ROSALDO, 1988: 86-87); as fronteiras entre "Aqui" e "Lá" tornaram-se menos nítidas (CLIFFORD, 1998); os "Outros" já não mais precisam ser exóticos para serem "Outros" (MARCUS \& FISCHER, 1986). Pacheco de Oliveira (1988) atentou para este fenômeno, criando, a partir daí, as noções de "pluralidade de referenciais" e de "campo político intersocietário", aplicando-as como instrumentais analíticos por meio dos quais os estudos dedicados às populações indígenas tornaram-se menos presos a concepções engendradas por perspectivas teóricas imbuídas de preceitos limitadores. Reconhecendo a coexistência de tradições diversas e conhecimentos virtuais num determinado contexto etnográfico, este autor contribuiu para tornar mais visível a dinâmica das relações interétnicas e abolir uma "percepção dualista da realidade (índios versus não-índios)” (MARTINS, 2004: 203).

Sendo assim, para quem esperava encontrar aqui um "sistema sexual genuinamente Potiguara", traduzido em discursos, comportamentos, agências completamente distintos dos observados em outros espaços socioculturais, o saldo é um tanto desalentador. Por outro lado, as diferenças estavam lá, não entre índios e não-índios, mas entre homens e mulheres, homens e homens, mulheres e mulheres. As diferenças, portanto, se davam nas interações e nos discursos desses sujeitos, atravessando marcadores que tangenciavam aspectos relacionados à classe, gosto, performances de gênero (masculinas ou femininas), comportamentos sexuais, moralidade, parentesco, amizade, afeto, competitividade, ciúmes, fofocas, idade, ocupação, local de moradia, status social e político, etc. Nesse sentido, nas relações cotidianas, indianidade e homossexualidade seguiam caminhos antes paralelos que cruzados. Em muitos casos, a questão das práticas e crenças religiosas, por exemplo, tinham um peso bem mais significativo na maneira de alguns sujeitos elaborarem e vivenciarem suas sexualidades do que o fator propriamente étnico.

Isto me levava ao encontro das palavras de Moore (2000: 16-17), quando esta afirma que "cada indivíduo tem uma história pessoal, e é na interseção dessa história com situações, discursos e identidades coletivas que reside a relação problemática entre estrutura e práxis, e entre o social e o indivíduo”. Para ela, porque o sujeito é o lugar de "subjetividades múltiplas e potencialmente contraditórias", os indivíduos podem assumir múltiplas posições de sujeito dentro de uma gama de discursos e práticas sociais (MOORE, 2000: 23-25, 35-36). As ambiguidades e contradições, as "negociações epistêmicas e morais", nesse sentido, se davam não apenas entre 
grupos ou pessoas, mas "dentro dos indivíduos mesmos" (BENHABIB, 2002: 31).

Epistemologicamente falando, o que foi colocado neste último tópico pode nos ajudar a evitar análises simplistas. No entanto, se as culturas e identidades são fluidas, se as diferenças socioculturais hoje em dia aparecem sob a égide das sutilezas, as desigualdades e os processos de exclusão são bastante visíveis e facilmente localizáveis. Os autores que me inspiraram e, sobretudo, as pessoas que tive o privilégio de conhecer durante o trabalho de campo, alertaram-me para o desafio político e moral que as ciências sociais têm de encarar de algum modo. Refiro-me às injustiças socioeconômicas e aos mais variados tipos de violência simbólica de que são alvo muitos dos atores que elegemos como "objeto de estudo". Não se trata aqui de vitimizá-los, tampouco de propor uma linha de ação ou defender uma antropologia aplicada. Mas se é verdade que o papel da etnografia consiste em proporcionar enredos capazes de fazer com que enxerguemos a nós e os outros como jogadores de um mesmo mundo (GEERTZ, 2000), contemplar as desigualdades como se estas fossem apenas diferenças pode levar não poucos pesquisadores a um mero narcisismo. Como escreveu Canclini (2007: 65-66), em nossa sociedade, índios não são apenas sujeitos etnicamente diferenciados, "são desempregados, pobres, migrantes sem documentos, homeless, desconectados". Para muitos deles, "o problema não é manter 'campos sociais alternativos', mas ser incluídos", "sem que isto atropele sua diferença nem os condene à desigualdade". Este mesmo autor acredita ter chegado o momento em que a antropologia "descobre ter vindo ao mundo" não "para consolar as minorias ou enfrentar quem busca subordiná-las, antes para descrever os esforços da convivência” (CANCLINI, 2007: 180). Descrever tais esforços, muitas vezes movidos a sangue (simbólico ou não), portanto, talvez seja moralmente mais justo e louvável do que calar-se diante deles.

\section{Referências bibliográficas}

AMORIM, Paulo Marcos de. Índios camponeses: os Potiguara de Baía da Traição. Dissertação de Mestrado, PPGAS/Museu Nacional/UFRJ, 1970.

APPADURAI, Arjun. Disjunção e diferença na economia cultural global. In: FEATHERSTONE, Mike (org.). Cultura global: nacionalismo, globalização $e$ modernidade. Petrópolis: Vozes, 1994. p. 311-27.

ARONSON, Dan R. Ethnicity as a Cultural System: An Introductory Essay. In: HENRY, Frances (org.). Ethnicity in the Americas. Paris: The Hague, 1976. pp. 9-2O.

AZEVEDO, Ana Lúcia Lobato de. A Terra Somo Nossa: uma análise de processos políticos na construção da terra Potiguara. Dissertação de Mestrado, PPGAS/Museu Nacional/UFRJ, 1986.

BARRETO FILHO, Henyo Trindade. Tapebas, Tapebanos e Pernas-de-Pau: etnogênese como processo social e luta simbólica. Dissertação de Mestrado, PPGAS/Museu Nacional/UFRJ, 1993.

BARTH, Fredrik. Grupos étnicos e suas fronteiras. In: POUTIGNAT, Philippe \& STREIFF-FENART, Jocelyne. Teorias da etnicidade. Seguido de grupos étnicos 
e suas fronteiras de Fredrik Barth. São Paulo: Fundação Editora da UNESP, 1998 [1969]. p. 185-227.

- Os grupos étnicos e suas fronteiras. In: $O$ guru, o iniciador $e$ outras variações antropológicas. Rio de Janeiro: Contra Capa, 2000 [1988]. p. 25-67.

BENHABIB, Seyla. The Claims of Culture: Equality and Diversity in the Global Era. Nova Jersey: Princeton University Press, 2002.

BHABHA, Homi. O local da cultura. Belo Horizonte: UFMG, 2001.

BOLTANSKI, Luc \& CHIAPELLO, Ève. O novo espírito do capitalismo. São Paulo: Martins Fontes, 2009.

BOURDIEU, Pierre. Homo academicus. Paris: Minuit, 1984.

. A economia das trocas linguísticas: o que falar quer dizer. São Paulo: Editora da Universidade de São Paulo, 1996.

A distinção: crítica social do julgamento. São Paulo/Porto Alegre: Edusp/Zouk, 2007.

BRAH, Avtar. Cartographies of Diaspora. Nova York: Routledge, 2002.

BRAH, Avtar \& PHOENIX, Ann. Ain't I a Woman? Revisiting Intersectionality. Journal of International Women's Studies, vol. 5, nº. 3, Bridgewater, 2004, p. $75-86$.

CANCLINI, Néstor García. Consumidores e cidadãos: conflitos multiculturais da globalização. Rio de Janeiro: Editora UFRJ, 1999.

Diferentes, desiguais e desconectados: mapas da interculturalidade. Rio de Janeiro: Editora UFRJ, 2007.

CARDOSO DE OLIVEIRA, Roberto. Identidade, etnia e estrutura social. São Paulo: Pioneira Editora, 1976.

- Caminhos da identidade: ensaios sobre etnicidade e multiculturalismo. São Paulo/Brasília: Editora Unesp/Paralelo 15, 2006.

CLIFFORD, James. A experiência etnográfica: antropologia e literatura no século XX. Rio de Janeiro: UFRJ, 1998.

COHEN, Ronald. Ethnicity: Problem and Focus in Anthropology. Annual Review of Anthropology (7), 1978, p. 379-403.

COSTA, Jurandir Freire. A inocência e o vício: estudos sobre o homoerotismo. Rio de Janeiro: Relume Dumará, 1992.

ERIKSEN, Thomas H. The Cultural Contexts of Ethnic Differences. Journal of the Royal Anthropological Institute, vol. 26, nº 1, 1991. 
ERIKSON, Erik. Identidade, juventude e crise. Rio de Janeiro: Jorge Zahar Editores, 1972 [1968].

FONSECA, Claudia. Família, fofoca e honra: etnografia de relações de gênero e violência em grupos populares. Porto Alegre: Editora da UFRGS, 2000.

FOUCAULT, Michel. O cuidado de si. Rio de Janeiro: Edições Graal, 1985. (História da sexualidade, v. 3).

FREYRE, Gilberto. Casa Grande \& Senzala: formação da família brasileira sob o regime da economia patriarcal. Rio de Janeiro: Record, 1994 [1933].

GEERTZ, Clifford. A interpretação das culturas. Rio de Janeiro: Jorge Zahar Editores, 1978.

Editor, 2000.

. Nova luz sobre a antropologia. Rio de Janeiro: Jorge Zahar

GOFFMAN, Erving. Estigma: notas sobre a manipulação da identidade deteriorada. Rio de Janeiro: LTC Editora, 1988.

GRÜNEWALD, Rodrigo de Azeredo. Regime de índio e faccionalismo: os Atikum da Serra do Umã. Dissertação de Mestrado, PPGAS/Museu Nacional/UFRJ, 1993.

GUPTA, Akhil \& FERGUSON, James. Beyond 'Culture': Space, Identity, and the Politics of Difference. Cultural Anthropology, vol. 7, $\mathrm{n}^{0}$ 1, 1992, p. 6-23.

HANNERZ, Ulf. Fluxos, fronteiras, híbridos: palavras-chave da antropologia transnacional. Mana, 3 (1), 1997, p. 7-39.

KEYES, Charles F. Towards a New Formulation of the Concept of Ethnic Group. Ethnicity, vol. 3, no 3,1976 , p. 202-213.

KODAMA, Kaori. Os filhos das brenhas e o Império do Brasil: a etnografia no Instituto Histórico e Geográfico do Brasil (1840-1860). Tese de Doutorado, Programa de Pós-Graduação em História Social da Cultura/PUC, Rio de Janeiro, 2005.

KUPER, Adam. Cultura: a visão dos antropólogos. Bauru: EDUSC, 2002.

LAIDLAW, James. For an Anthropology of Ethics and Freedom. The Journal of the Royal Anthropological Institute, vol. 8, $\mathrm{n}^{0}$ 2, jun/2002.

LEAL, Andréa Fachel. Práticas sexuais no contexto da conjugalidade: o que implica a intimidade? In: HEILBORN, Maria Luiza; DUARTE, Luiz Fernando Dias; PEIXOTO, Clarice; BARROS, Myriam Lins de (orgs). Sexualidade, família e ethos religioso. Rio de Janeiro: Garamond, 2005. p. 61-85.

LEMERT, Charles. Pós-modernismo não é o que você pensa. São Paulo: Edições Loyola, 2000. 
MARCUS, George. Identidades passadas, presentes e emergentes: requisitos para etnografias sobre a modernidade no final do século XX ao nível mundial. Revista de Antropologia, vol. 34, São Paulo, 1991, p. 197-220.

MARCUS, George \& FISCHER, Michael (orgs.). Anthropology as Cultural Critique: An Experimental Moment in the Human Sciences. Chicago: University of Chicago Press, 1986.

MARTINS, Silvia Aguiar Carneiro. Os caminhos das aldeias Xucuru-Kariri. In: PACHECO DE OLIVEIRA, João (org.). A viagem da volta: etnicidade, política e reelaboração cultural no Nordeste indígena. Rio de Janeiro: Contra Capa Livraria/LACED, 2004. p. 199-230.

MCCLINTOCK, Anne. Couro imperial: raça, gênero e sexualidade no embate colonial. Campinas, SP: Editora da Unicamp, 2010.

MOONEN, Frans e MAIA, Luciano Mariz. Etnohistória dos índios Potiguara: ensaios, relatórios, documentos. João Pessoa: PR/PB-SEC/PB, 1992.

MOORE, Henrietta L. Fantasias de poder e fantasias de identidade: gênero, raça e violência. Cadernos Pagu (14), Núcleo de Estudos de Gênero Pagu/Unicamp, 2000. p. 13-44.

NAGATA, Judith A. What is Malay? Situational Selection of Ethnic Identity in a Plural Society. American Ethnologist, vol. 1, nº 2, 1974, p. 331-350.

NAGEL, Joane. Race, Ethnicity, and Sexuality: Intimate Intersections, Forbidden Frontiers. Nova York/Oxford: Oxford University Press, 2003.

OKAMURA, Jonathan Y. Situational Ethnicity. Ethnic and Racial Studies, vol. $4, \mathrm{n}^{\circ} 4,1981$, p. 452-465.

PACHECO DE OLIVEIRA, João. "O nosso governo": os Ticuna e o Regime Tutelar. São Paulo: Editora Marco Zero, 1988.

. A problemática dos "índios misturados" e os limites dos estudos americanistas: um encontro entre antropologia e história. In: Ensaios em antropologia histórica. Rio de Janeiro: Editora UFRJ, 1999. p. 99-123.

. Uma etnologia dos "índios misturados"? Situação colonial, territorialização e fluxos culturais. In: PACHECO DE OLIVEIRA, João (org.). $A$ viagem da volta: etnicidade, política e reelaboração cultural no Nordeste indígena. Rio de Janeiro: Contra Capa Livraria/LACED, 2004. p. 13-42.

PALITOT, Estêvão Martins. Os Potiguara da Baía da Traição e Monte-Mór: História, Etnicidade e Cultura. Dissertação de mestrado, PPGS/UFPB, 2005.

- A terra dos índios esquecidos: o processo de territorialização dos Potiguara de Monte-Mór. Trabalho publicado no âmbito do V Prêmio Antropologia e direitos humanos da Associação Brasileira de Antropologia/Fundação Ford, com o tema "Dilemas da (Des)Igualdade na Diversidade”, edição 2008. 
POUTIGNAT, Philippe \& STREIFF-FENART, Jocelyne. Teorias da etnicidade. Seguido de grupos étnicos e suas fronteiras de Fredrik Barth. São Paulo: Fundação Editora da UNESP, 1998.

RAMOS, Alcida. A Hall of Mirroirs. Critique of Anthropology, vol. 11, $\mathrm{n}^{0}$ 2, 1991, p. 155-169.

ROSALDO, Renato. Ideology, Place and People without Culture. Cultural Anthropology, vol. 3, no 1, 1988, p. 77-87.

SAID, Edward. Orientalism: Western Representations of the Orient. Londres: Routledge \& Kegan Paul, 1978.

SIMÕES, Júlio Assis. Homossexualidade masculina e curso da vida : pensando idades e identidades. In: PISCITELLI, Adriana; GREGORI, Maria Filomena; CARRARA, Sérgio (orgs.). Sexualidade e saberes: convenções e fronteiras. Rio de Janeiro: Garamond, 2004. p. 415-447.

STOLCKE, Verena. Is Sex to Gender as Race is to Ethnicity? In: VALLE, Teresa del (org.). Gendered Anthropology. Londres: Routledge, 1993. p. 17-37.

TOTA, Martinho. Entre as diferenças: gênero, geração e sexualidades em contexto interétnico. Tese de doutorado, PPGAS/Museu Nacional/UFRJ, 2012.

TREXLER, Richard C. Sex and Conquest: Gendered Violence, Political Order, and the European Conquest of the Americas. Ithaca, Nova York: Cornell University Press, 1995.

VIEIRA, José Glebson. A (Im)pureza do sangue e o perigo da mistura: uma etnografia do grupo indígena Potyguara da Paraíba. Dissertação de Mestrado, PPGAS/UFPR, 2001.

WEBER, Max. Relações comunitárias étnicas. In: Economia e Sociedade: fundamentos da sociologia compreensiva. Brasília: Editora da UnB, 1991 [v. 1]. p. 267-277.

YOUNG, Robert J. C. Desejo colonial: hibridismo em teoria, cultura e raça. São

Paulo: Perspectiva, 2005. 